\title{
Augmentation of protein-derived acetic acid production by heat- alkaline-induced changes in protein structure and conformation
}

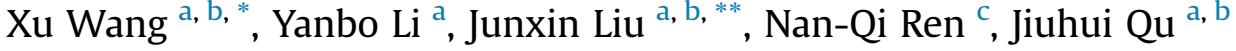 \\ ${ }^{a}$ Research Center for Eco-Environmental Sciences, Chinese Academy of Sciences, Beijing 100085, China \\ b State Key Joint Laboratory of Environment Simulation and Pollution Control, Research Center for Eco-Environmental Sciences, Chinese Academy of \\ Sciences, Beijing 100085, China \\ ' State Key Laboratory of Urban Water Resource and Environment, School of Municipal and Environmental Engineering, Harbin Institute of Technology, \\ Harbin 150090, China
}

\section{A R T I C L E I N F O}

\section{Article history:}

Received 11 July 2015

Received in revised form

27 October 2015

Accepted 28 October 2015

Available online 31 October 2015

\section{Keywords:}

Waste activated sludge

Fermentation

Pretreatment

Acetic acid

Protein structure and conformation

Economic analysis

\begin{abstract}
A B S T R A C T
Waste-derived acetic acid (HAc) is an attractive feedstock for microbe-mediated biofuel production. However, fermentative conversion of HAc from waste-activated sludge (WAS) has low yield because of the high concentration of proteins not readily utilizable by microorganisms without prior hydrolysis. We investigated a combined technology for HAc augmentation during sludge protein fermentation. The maximal HAc yield increased over two-fold, reaching $0.502 \pm 0.021 \mathrm{~g} / \mathrm{g}$ protein $(0.36 \pm 0.01 \mathrm{~g}$ COD $/ \mathrm{g}$ COD, $\sim 52 \%$ of the total volatile fatty acids) when synthetic sludge protein was heated at $120{ }^{\circ} \mathrm{C}$ for $30 \mathrm{~min}$, treated at $\mathrm{pH} 12$ for $24 \mathrm{~h}$, and fermented at $\mathrm{pH} 9$ for $72 \mathrm{~h}$. Comprehensive analysis illustrated that the heat-alkaline pretreatment significantly induced protein fragmentation, simultaneously increasing the efficiency of protein biohydrolysis (from $35.5 \%$ to $85.9 \%$ ) by inducing conformational changes indicative of protein unfolding. Consequently, the native $\alpha$-helix content was decreased from $67.3 \%$ to $32.5 \%$ by conversion to an unordered shape, whose content increased from $27.5 \%$ to $45.5 \%$; disulfide bonds were cleaved, whereas the main S-S stretching pattern was altered from gauche-gauche-gauche to gauchegauche-trans, consequently causing increased protein susceptibility to proteolytic hydrolysis (76.3\% vs. 47.0\%). Economic analysis indicated that anaerobic fermentation with appropriate heat-alkaline pretreatment is a cost-effective approach for waste conversion to energy sources such as HAc.
\end{abstract}

(C) 2015 Elsevier Ltd. All rights reserved.

\section{Introduction}

As concerns over the depletion of oil reserves and the environmental and social impacts of oil combustion byproducts escalate, it is essential to develop alternative approaches to energy production and to diversify sustainable and economically viable energy sources in the commercial market (Dangerman and Schellnhuber, 2013). One of the attractive strategies to satisfy both needs is the utilization of waste-derived feedstock for the generation of different forms of energy via bioconversion (Nasidi et al., 2010). An example is the production of fermentative volatile fatty acids (VFA), an inexpensive energy source that can be used

\footnotetext{
* Corresponding author. Research Center for Eco-Environmental Sciences, Chinese Academy of Sciences, Beijing 100085, China.

** Corresponding author. Research Center for Eco-Environmental Sciences, Chinese Academy of Sciences, Beijing 100085, China.

E-mail address: xuwang@rcees.ac.cn (X. Wang).
}

to generate electricity and various valuable fuels such as biogas, hydrogen, and biodiesel (Lee et al., 2014). Waste-activated sludge (WAS) obtained through biological treatment of wastewater contains high quantities of organic matter, which can serve as a favorable feedstock for VFA synthesis through anaerobic fermentation (Li et al., 2011), thus minimizing disposable waste generation (Wang et al., 2015, 2012).

It is also increasingly recognized that the efficiency of downstream energy production is critically affected by VFA type, and acetic acid (HAc) has been identified as a promising feedstock (Wang et al., 2013). Previous studies indicate that HAc used as a substrate in a microbial fuel cell is preferable to other VFAs in terms of amount, coulombic efficiency, and electricity generation (Freguia et al., 2010; Chae et al., 2009). Another example is VFA-based biogas production under anaerobic conditions; among all VFAs tested, methanogenic bacteria had the highest tolerance to HAc (Wang et al., 2009). Hydrogen production is also much sensitive to VFAs used in fermentation and microbial electrolysis systems, and 
hydrogen generation can be enhanced by elevating the HAc fraction in the feed (Uyar et al., 2009; Liu et al., 2012a). A study on VFAdriven lipid production showed that VFA feed containing higher ratios of HAc generated the highest lipid content (Fei et al., 2011). However, strategies to improve HAc yield during WAS dark fermentation have not been extensively investigated.

Proteins are essential components of microbial cells and extracellular polymeric substances and account for $50 \%-60 \%$ of the organic component in WAS (Lu et al., 2012). In anaerobic bioconversion, proteins are hydrolyzed by extracellular enzymes to shortchain polypeptides and amino acids and then fermented to VFAs that are metabolized by acetogenic and homoacetogenic microorganisms to generate HAc. However, naturally folded proteins are not susceptible to protease cleavage (Halabi et al., 2009), and because protein hydrolysis is the rate-limiting step, it retards HAc generation from WAS. Recently, protein hydrolysis has been found to be accelerated via manipulation of protein native conformation (Xiao et al., 2014); nevertheless, the process inhibited homoacetogenesis, emphasizing the need for enhanced hydrogen production from protein-containing wastewater.

It is well known that heat and alkaline pretreatments are alternative approaches to facilitate solubilization of the extracellular polymeric material in the sludge and to break cell walls, resulting in the substantial release of intracellular organic matter for further VFA generation. However, the effects of these alternative pretreatment approaches on protein conformation and microbial conversion to HAc during anaerobic fermentation of WAS have not been fully investigated. In this study, we investigated a combined technology to improve the yield of HAc in dark fermentation of sludge protein; initial pretreatment of sewage sludge was applied at high temperature of $120^{\circ} \mathrm{C}$ for $30 \mathrm{~min}$, followed by incubation at $\mathrm{pH} 12$ at room temperature for $24 \mathrm{~h}$ and fermentation at $\mathrm{pH} 9$ for HAc production. This approach was first tested in the production of HAc from bovine serum albumin (BSA). Subsequently, the efficiency of BSA fragmentation and denaturation and the changes in its secondary structure were further analyzed by sodium dodecyl sulfate-polyacrylamide gel electrophoresis, circular dichroism, dynamic light scattering, as well as excitation-emission matrix fluorescence spectroscopy and Raman spectroscopy among other techniques. Finally, the feasibility of the combined approach for the improvement of HAc yield was also verified using real sewage sludge along with an economic analysis.

\section{Methodology}

\subsection{Sewage sludge and seed microorganisms}

In this work, the sewage sludge was collected from a secondary clarifier of a WWTP in Northern China. The sludge was concentrated by allowing it to settle for approximately $24 \mathrm{~h}$ and was then air-dried for 10 days at $24^{\circ} \mathrm{C}$, ground in a hammer mill and screened with a $0.45 \mathrm{~mm}$ mesh, and finally stored at $-20^{\circ} \mathrm{C}$ for further tests. The main characteristics of the concentrated sludge are as follows: $\mathrm{pH}, 6.92 \pm 0.05$; total suspended solids (TSS), $16.8 \pm 0.9 \mathrm{~g} / \mathrm{L}$; volatile suspended solids (VSS), $13.7 \pm 0.6 \mathrm{~g} / \mathrm{L}$; total chemical oxygen demand (TCOD), $19.2 \pm 1.4 \mathrm{~g} \mathrm{COD} / \mathrm{L}$; soluble chemical oxygen demand (SCOD), $0.10 \pm 0.01 \mathrm{~g} \mathrm{COD} / \mathrm{L}$; total protein, $9.4 \pm 0.5 \mathrm{~g} \mathrm{COD} / \mathrm{L}$; total carbohydrate, $1.19 \pm 0.05 \mathrm{~g}$ COD/L; and lipid, $0.28 \pm 0.02 \mathrm{~g}$ COD/L. In addition, seeding sludge was obtained from the same site and then cultured prior to seeding microorganisms (see Supplementary information). Subsequently, the seeding sludge was centrifuged at $3000 \times g$ for 20 min to remove the soluble organics and washed twice with distilled water. The centrifuged sludge sediment was used as the seed inoculum for HAc production experiments.

\subsection{Effects of heat and alkaline pretreatment on HAc production from synthetic sludge protein}

Sewage sludge contains multiple types of proteins. To better investigate the effects of pretreatment on HAc production from sludge protein fermentation and to clearly understand the fate of the proteins in the process, pure protein, i.e., bovine serum albumin (BSA, Sigma-A7030) was used as a substrate model for mechanistic explorations. Specifically, the BSA sample was added into $500-\mathrm{mL}$ serum vials at $1.80 \mathrm{~g} / \mathrm{L}$ in $250 \mathrm{~mL}$ to test four different pretreatment conditions. The heat-pretreated sample (H-BSA) was autoclaved at $120^{\circ} \mathrm{C}$ and $117.6 \mathrm{kPa}$ (VARIOKLAV steam sterilizer) for $30 \mathrm{~min}$ and then cooled to room temperature $\left(24 \pm 1^{\circ} \mathrm{C}\right)$. The alkaline-pretreated sample (A-BSA) was mixed with $6 \mathrm{M}$ sodium hydroxide $(\mathrm{NaOH})$ to adjust the $\mathrm{pH}$ to 12 , stirred for $30 \mathrm{~min}$, and placed in a temperature-controlled chamber at $24{ }^{\circ} \mathrm{C}$ for $24 \mathrm{~h}$. The third sample (HA-BSA) was subjected to a combination of heat and alkaline pretreatment, i.e., 30 -min heating at $120^{\circ} \mathrm{C}$ and 24 -h incubation at $\mathrm{pH} 12$ at room temperature. The untreated raw sample (R-BSA) was used as the control. No microorganisms were added during the pretreatments of synthetic protein samples. After the pretreatments, $1.0 \mathrm{~g}$ of $\mathrm{NaHCO}_{3}$ (buffer salt), $35 \mathrm{mg}$ of $\mathrm{K}_{2} \mathrm{HPO}_{4} \cdot 3 \mathrm{H}_{2} \mathrm{O}$ (phosphorus source), $1.0 \mathrm{~mL}$ of trace element solution (g/L: EDTA2Na, 2.0; $\mathrm{FeSO}_{4} \cdot 7 \mathrm{H}_{2} \mathrm{O}, 2.0 ; \mathrm{H}_{3} \mathrm{BO}_{3}, 0.1 ; \mathrm{CoCl}_{2} \cdot 6 \mathrm{H}_{2} \mathrm{O}, 0.1 ; \mathrm{ZnCl}_{2}, 0.1$; $\mathrm{Cu}\left(\mathrm{NO}_{3}\right)_{2} \cdot 5 \mathrm{H}_{2} \mathrm{O}, \quad 0.05 ; \quad \mathrm{MnCl}_{2} \cdot 4 \mathrm{H}_{2} \mathrm{O}, \quad 0.1 ; \quad \mathrm{Na}_{2} \mathrm{MoO}_{4}, \quad 0.75$; $\mathrm{NiCl}_{2} \cdot 6 \mathrm{H}_{2} \mathrm{O}, 0.02$ ), and $25 \mathrm{~mL}$ of seed microorganisms were added to each vial. The mixture was adjusted to $\mathrm{pH} 7$ by $6 \mathrm{M} \mathrm{HCl}$ or $6 \mathrm{M}$ $\mathrm{NaOH}$ followed by nitrogen flush and rubber stopper sealing, and HAc fermentation was conducted at $34 \pm 1^{\circ} \mathrm{C}$ in an air-bath shaker (150 rpm).

Additionally, the effects of $\mathrm{pH}$ on HAc production from proteins were explored using HA-BSA as a substrate at pH 7 (control), 8, 9, 10 , and 11 ; the $\mathrm{pH}$ was maintained by the addition of $6 \mathrm{M} \mathrm{NaOH}$ or $6 \mathrm{M} \mathrm{HCL}$ throughout the experiment.

\subsection{Enzymatic protein hydrolysis}

Protein accessibility to proteolysis after heat and alkaline pretreatment was evaluated as protein enzymolysis efficiency $\left(E_{\text {pro }}\right)$, which can be calculated as follows:

$E_{\text {pro }}=\frac{\Delta C_{\text {pro }}}{C_{\text {pro,initial }}}$

where $\Delta C_{\text {pro }}$ is the difference in protein concentration $(\mathrm{g} / \mathrm{L})$ in the sample before and after the experiment, and $C_{\text {pro,initial }}$ is the initial protein concentration $(\mathrm{g} / \mathrm{L})$ in the sample.

Using eq. (1), $\Delta C_{\text {pro }}$ can be further determined as follows (Miron et al., 2000):

$\Delta C_{\text {pro }}=\frac{C_{T N}}{\eta_{\text {pro }, n}}$

where $\eta_{\text {pro, } n}$ is the average fraction of nitrogen content in protein (Miron et al., 2000), i.e., 0.16; and $C_{T N}$ is the concentration of total nitrogen (TN) in the supernatant.

Pronase E, also called actinase E, is a protease derived from Streptomyces griseus and is widely used to achieve complete enzymatic hydrolysis of a protein (e.g., in the analysis of amino acid composition) because it contains more than 10 effective proteolytic components (Bermejo-Barrera et al., 1999). Moreover, Pronase E was also applied recently to decrease solid content and enhance anaerobic digestion of sewage sludge (Roman et al., 2006). Accordingly, Pronase E was used as a model protease and added at the concentration of $50 \mathrm{mg} / \mathrm{L}$ to the reactors containing R-BSA and 
HA-BSA, and the test was performed under the conditions described above. At set intervals, $5 \mathrm{~mL}$ of the mixture was sampled and immediately treated at $100{ }^{\circ} \mathrm{C}$ for $10 \mathrm{~min}$ to inhibit enzyme activity. After cooling to room temperature, the residual protein in sample was precipitated by adding $5 \mathrm{~mL}$ of $15 \%$ trichloroacetic acid, and the mixture was centrifuged at $3000 \times g$ for $20 \mathrm{~min}$. Subsequently, the supernatant was collected for determination of $C_{T N}$ using a TOC/TN analyzer (Shimadzu TOC-VCPH/TNM-1).

\subsection{Protein structure determination}

To determine protein secondary structure, circular dichroism (CD) spectra were acquired using an automatic recording spectropolarimeter (JASCO J-715). The secondary structure content in the samples was estimated using the curve-fitting method of the far-UV $\mathrm{CD}$ spectrum and the JASCO secondary structure manager (Greenfield, 2006). The spectra were acquired at $25 \pm 0.1^{\circ} \mathrm{C}$ with a scan speed of $50 \mathrm{~nm} / \mathrm{min}$ and spectral bandwidth of $1 \mathrm{~nm}$; each spectrum represented the average of four scans. The secondary structure was measured over the wavelength range of $200-250 \mathrm{~nm}$ using a cuvette with a path length of $1 \mathrm{~cm}$ against distilled water as a blank and estimated by the mean residue ellipticity (MRE, $\mathrm{deg} \cdot \mathrm{cm}^{2} / \mathrm{dmol}$ ):

$M R E=\frac{\theta_{o b s} M}{n l C}$

where $\theta_{o b s}$ is $\mathrm{CD}$ in millidegrees ( $\mathrm{m} \mathrm{deg}$ ), $M$ is protein molecular weight ( $\mathrm{g} / \mathrm{dmol}), n$ is the number of amino acids (583 in BSA), $l$ is cuvette path length $(1 \mathrm{~cm})$, and $C$ is protein concentration $(\mathrm{g} / \mathrm{L})$.

The intensity-weighted average protein hydrodynamic diameter $\left(D_{h}, \mathrm{~nm}\right)$ was determined by the dynamic light scattering (DLS) technique using a Zetasizer system (Malvern Nano ZS90) with a $\mathrm{He}-\mathrm{Ne}$ laser operated at a wavelength of $633 \mathrm{~nm}$ and a scattering angle of $90^{\circ}$. The size was estimated as the mean value of three runs. The data were analyzed using Dynamics 6.10.0.10 software at the optimized resolution. $D_{h}$ was estimated by autocorrelation analysis of scattered light intensity using the translational diffusion coefficient based on the Stokes-Einstein equation:

$D_{h}=\frac{k T}{3 \pi \eta D_{W}^{25^{\circ} \mathrm{C}}}$

where $k$ is Boltzmann's constant, $T$ is absolute temperature, $\eta$ is water viscosity, and $D_{w}^{25^{\circ} \mathrm{C}}$ is the translational diffusion coefficient.

Three-dimensional excitation-emission matrix (EEM) fluorescence spectroscopy (JASCO FP-6500) was used to further analyze the R-BSA and HA-BSA composition. The sample was filtered through a $0.50-\mu \mathrm{m}$ hydrophilic membrane and diluted to an appropriate concentration prior to EEM analysis. The spectra were obtained with the excitation and emission wavelengths gradually increased from 200 to $500 \mathrm{~nm}$ at $1 \mathrm{~nm}$ step to obtain the EEM fluorescence.

Raman spectroscopy (Jobin Yvon HR-800) was used to characterize the conformation of protein disulfide bridges. Raman spectra were acquired in the range of $100-1600 \mathrm{~cm}^{-1}$ using a He-Ne laser beam and irradiation at a wavelength of $632.8 \mathrm{~nm}$; each spectrum was determined as the accumulated average of three exposures at room temperature. To quantify protein structural composition, the spectra were normalized to the intensity of the phenylalanine band, i.e., 1000 at $1004 \mathrm{~cm}^{-1}$ (Tuma, 2005). The Raman spectra were fitted to the Gaussian model using the Origin Pro 9.1 software.

\subsection{HAc production by real WAS fermentation}

The sewage sludge (details in Section 2.1) was diluted and then used for fermentative HAc production. The HAc yield of the untreated (R-WAS) and heat-alkaline pretreated (HA-WAS) sludge samples was compared in two identical reactors, where fermentation $\mathrm{pH}$ was set at 7 and 9, respectively, using $6 \mathrm{M} \mathrm{HCl}$ or $6 \mathrm{M}$ $\mathrm{NaOH}$. The seed microbes and other operational and analytical parameters were as described above.

\subsection{Other analytical methods}

Determinations of $\mathrm{pH}$, protein, carbohydrate, lipid, VFAs, COD, TSS, and VSS content were performed as previously described (Cai et al., 2004). Moreover, the conversion factor of protein to COD was set as $1.5 \mathrm{~g} \mathrm{COD} / \mathrm{g}$ protein, according to a previous report (Miron et al., 2000). The detailed analytical procedures for biogas component analysis, sodium dodecyl sulfate-polyacrylamide gel electrophoresis (SDS-PAGE), fluorescence in situ hybridization (FISH), and acid-forming enzyme activity analysis are provided in the Supplementary information.

\subsection{Statistical analysis}

The results are presented as the mean \pm standard deviation of triplicate experiments performed in the same conditions. The statistical differences between samples were analyzed using IBM SPSS statistics 21.0 software; $p<0.05$ was considered statistically significant.

\section{Results and discussion}

\subsection{Comparison of pretreatment and fermentation approaches to HAc production}

First, the effect of different pretreatments of synthetic sludge protein on the yield of HAc produced by dark fermentation was examined at $\mathrm{pH} 7$ (Fig. 1a). HAc production started after $6 \mathrm{~h}$ and the yield increased with fermentation time in all the tested samples; however, after $72 \mathrm{~h}$, the increase was not significant $(p>0.05)$. Therefore, the effects of alternative pretreatments on HAc yield were comparatively evaluated at the fermentation time of $72 \mathrm{~h}$. HABSA fermentation demonstrated 1.11-, 1.47-, 2.24-fold higher HAc yield $(0.416 \pm 0.016 \mathrm{~g} / \mathrm{g}$ protein $)$ than A-BSA $(0.376 \pm 0.015 \mathrm{~g} / \mathrm{g}$ protein), H-BSA (0.283 $\pm 0.025 \mathrm{~g} / \mathrm{g}$ protein), and R-BSA (control; $0.186 \pm 0.018 \mathrm{~g} / \mathrm{g}$ protein), respectively. Therefore, the combination of heat $\left(120^{\circ} \mathrm{C}\right)$ and alkaline $(\mathrm{pH} 12)$ pretreatment caused a significant increase in HAc production.

Consequently, the HA-BSA was used to further test the effect of fermentation $\mathrm{pH}$ on HAc generation (Fig. 1b). Increases in $\mathrm{pH}$ significantly stimulated HAc production over time, and the maximal HAc yield $(0.502 \pm 0.021 \mathrm{~g} / \mathrm{g}$ protein $)$-which was approximately 2.70-fold higher than that of the control (Fig. 1a)was observed at pH 9 after 72 h of fermentation. In Fig. S1, HA-BSA fermentation also represented a much higher total VFA yield $(0.790 \pm 0.031 \mathrm{~g} / \mathrm{g}$ protein, or $0.70 \pm 0.03 \mathrm{~g} \mathrm{COD} / \mathrm{g}$ COD $)$ than did by R-BSA fermentation $(0.346 \pm 0.014 \mathrm{~g} / \mathrm{g}$ protein, or $0.32 \pm 0.01 \mathrm{~g}$ $\mathrm{COD} / \mathrm{g}$ COD) and other recent literature (Morgan-Sagastume et al., 2015; 2011; Jie et al., 2014). Despite the findings indicating that fermentation at $\mathrm{pH} 9$ is the optimum condition for VFA accumulation while feeding with heat-alkaline pretreated substrates, additional studies also report that maximal VFA yield was achieved in the untreated-substrate fed reactor when fermentation was carried out at pH 10 (Yuan et al., 2006). Indeed, the specific ranges of the optimum $\mathrm{pH}$ conditions for VFA production are dependent on the types of substrate used. Thus far, the reported optimal $\mathrm{pH}$ values are in the range of 8-11 for VFA accumulation during the anaerobic fermentation of sewage sludge (Lee et al., 2014). Overall, 

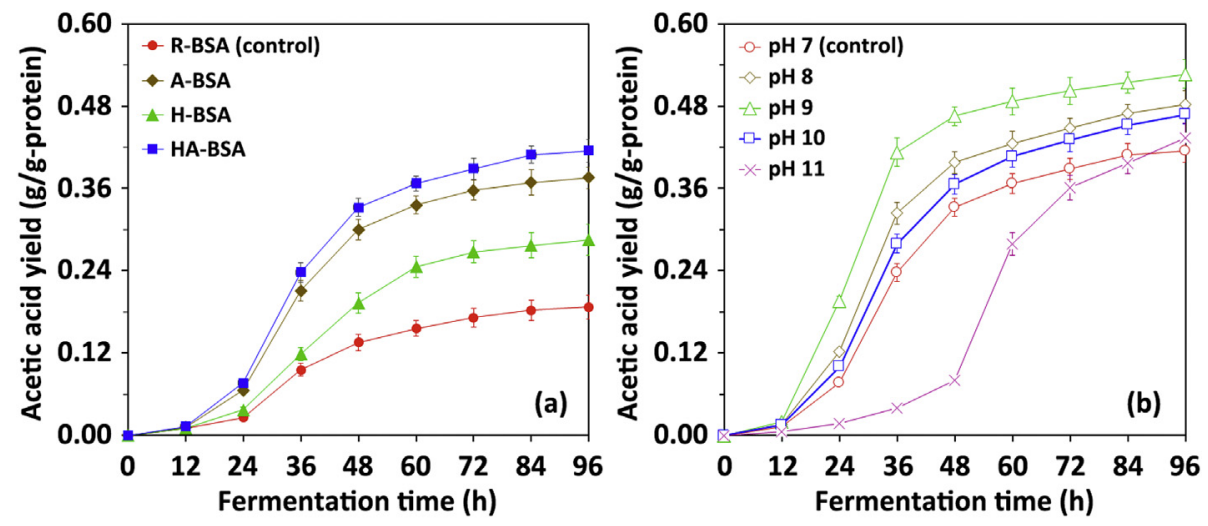

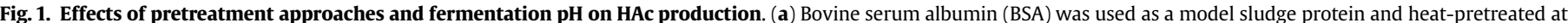

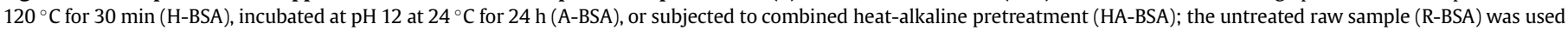

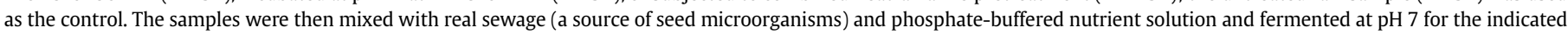
times. (b) HA-BSA was fermented at different $\mathrm{pH}$ for the indicated times. The data are expressed as the mean \pm standard deviation of triplicate tests.

the heat-alkaline pretreatment combined with anaerobic fermentation at $\mathrm{pH} 9$ for $72 \mathrm{~h}$ was considered as an effective approach to augment HAc production in this work.

Subsequently, the FISH assay was performed for a better understanding of the augmentation of HAc yield at fermentation $\mathrm{pH} 9$ (see Fig. S2 for details). Further images analysis demonstrated that the average ratio of bacteria to archaea in the reactors was 101:1 ( $\mathrm{pH}$ 9) and 27:1 (control, $\mathrm{pH}$ 7). The ratio of bacteria to archaea in these two reactors was aligned with their observed HAc yields, implying the increased proportion of bacteria probably contributed to the augmented HAc yield. Many bacteria have been reported to be capable of producing HAc under anaerobic conditions (Mitchell, 1998). Some species of Clostridia, which are closely related to Clostridium spp., have been shown to generate HAc under obligate alkaliphilic (pH 8-12) conditions (Zhilina et al., 2005). Additional species of Clostridia, which were similar to the genus Anaerobranca, have been documented to be the predominant microorganism in alkaline fermentation conditions (Zhang et al., 2010). As previously reported (Prowe and Antranikian, 2001; Gorlenko et al., 2004), the genus Anaerobranca comprises only a few species among anaerobic microorganisms that have the capacity to convert proteins to HAc as key final product at $\mathrm{pH} 6-10$ and temperature $30-70{ }^{\circ} \mathrm{C}$. Additionally, the requirement of Anaerobranca needs sodium ions (Engle et al., 1995). In this work, $6 \mathrm{M}$ sodium hydroxide was applied to ensure alkaline conditions, and substantial amounts of sodium ions were present in the reactor, which may explain why HAc accumulated at $\mathrm{pH}$ 9. Since an alkaline environment is not conducive to methanogenesis, the hydrolysis and the susceptibility of the available substrates for the acidogenic bacteria might be key factors to augment HAc production, rather than the competition between the acidogenic bacteria and the methanogens. Thus, future efforts should be devoted to decipher the effect of heat-alkaline stimulation on the susceptibility of substrates to acidogenic bacteria responsible for improved HAc generation.

\subsection{Effect of heat-alkaline stimulation on protein susceptibility to hydrolysis}

In dark fermentation, hydrolysis is a critical step for HAc production from protein. Thus, we subsequently focused on investigating the effects of the heat-alkaline pretreatment on protein hydrolysis and susceptibility to proteolytic degradation.

Protein fragmentation is the process of breaking up proteins into smaller fragments, making them more accessible for further anaerobic conversions (Kim et al., 2003). Consequently, the fragmentation degree of HA-BSA was indirectly determined by SDS-PAGE (see Fig. 2). BSA without pretreatment (R-BSA, lane b) was used as a negative control for protein fragmentation; one thicker band at 50-60 kDa and faint bands below $200 \mathrm{kDa}$ were observed, which agreed with previous findings (Ajandouz et al., 2008), notwithstanding the characteristic bands vary slightly among different commercial BSA products. However, the characteristic bands of native BSA had noticeably disappeared for the HABSA, and smeared bands were shown in the right side (lance c) of Fig. 2, indicating that heat-alkaline treatment may have successfully fragmented BSA into smaller pieces.

Moreover, $E_{\text {pro }}$ measurements also indicated critical effects of the heat-alkaline pretreatment on protein susceptibility to proteolysis (Fig. 3a). After $1 \mathrm{~h}$, the $E_{\text {pro }}$ of the HA-pretreated sample was significantly higher than that of the control (76.3\% vs. 47.0\%). Protease activity was also enhanced by the heat-alkaline pretreatment (Fig. 3b), and the protein hydrolysis efficiency in HA-BSA increased to $85.5 \%$ compared to $35.9 \%$ in R-BSA.

Protein secondary structure directly influences the susceptibility to enzymatic hydrolysis, which can be substantially enhanced after protein unfolding (Renard et al., 2014). Protein conformation is determined by hydrogen bonding-mediated folding of the peptide backbone into $\alpha$-helices and $\beta$-sheets. We therefore used CD to compare conformational transitions of protein molecules in R-BSA and HA-BSA samples. As shown in Fig. 4a, the R-BSA spectrum had two negative peaks at 208 and $222 \mathrm{~nm}$, generally characteristic of an $\alpha$-helical structure (Greenfield, 2006). However, the CD signal of HA-BSA decreased significantly, suggesting that the pretreatment induced changes in the secondary structure of the protein molecules. The protein structural content displayed as tree maps (Fig. 4b) further indicates that R-BSA consisted of $67.3 \pm 1.1 \% \alpha$ helices, $15.9 \pm 0.2 \% \beta$-sheets, $7.4 \pm 0.6 \% \beta$-turns, and $9.3 \pm 1.5 \%$ unordered structure, which is consistent with previous reports (Reed et al., 1976). After heat-alkaline pretreatment, the $\alpha$-helix content decreased to $33.3 \%$, which is almost half of that in the control. These data demonstrate that the heat-alkaline stimulation decreased ordered protein folding, consequently increasing the amount of unordered structure (Fig. 4b) and suggesting that the heat-alkaline stimulation approach significantly facilitates protein denaturation (Fig. 5a). Moreover, DLS is another useful technique to explore protein folding based on size (Mitra et al., 2007). Fig. 5b shows denaturation of HA-pretreated proteins, as evidenced by a 2.04-fold increase in average hydrodynamic diameter compared to that of the untreated protein.

EEM spectroscopy enables comprehensive profiling of protein 


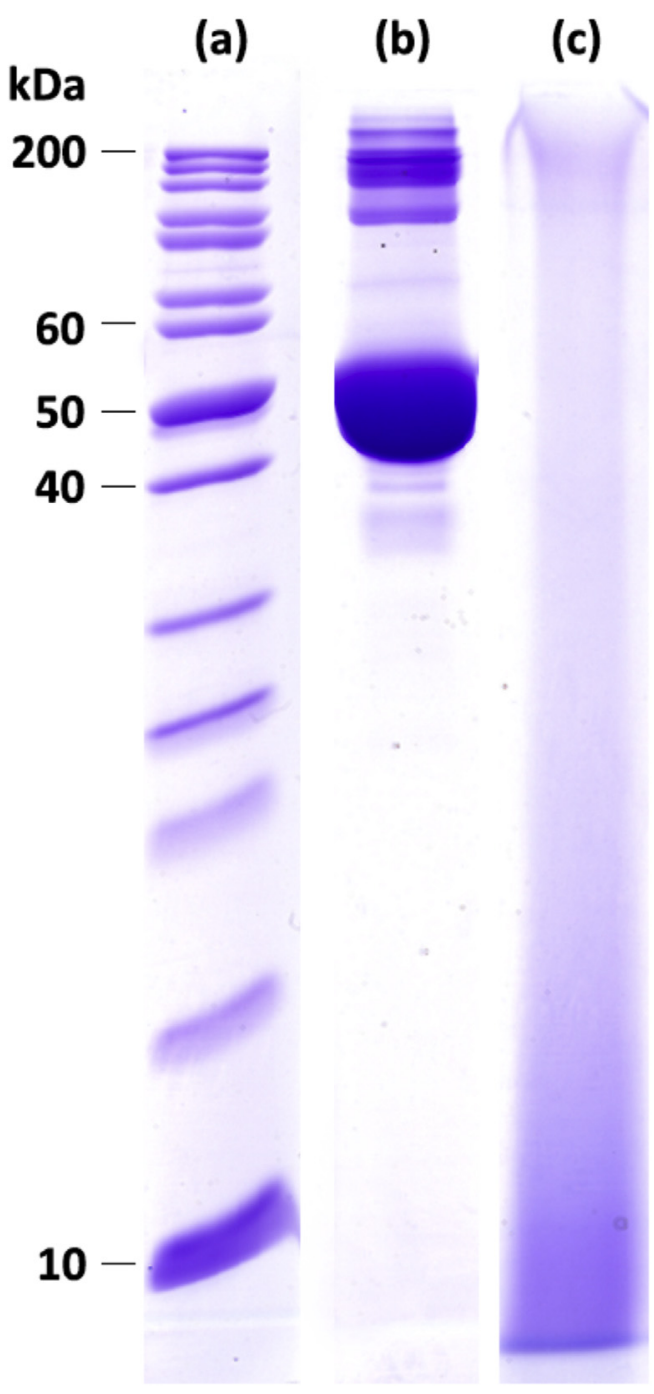

Fig. 2. SDS-PAGE images indicating the degree of protein fragmentation following heat-alkaline pretreatment. (a) Protein markers (10-200 kDa), (b) R-BSA, and (c) HABSA.

fluorescence in complex mixtures over a range of excitation and emission wavelengths, thus providing superior analytical potential for fluorescence measurements (Sheng and Yu, 2006). Here, we acquired EEM spectra to reveal the structural transitions in the HABSA sample, represented by transformations in the tryptophan microenvironment induced by protein denaturation (Bhattacharya et al., 2011). In Fig. 5c, the maximum peak fluorescence intensity of the HA-treated sample was substantially lower than that of R-BSA $\left(2.6 \times 10^{6}\right.$ vs. $4.7 \times 10^{6}$ a.u. $)$, whereas the maximum excitation and emission wavelengths demonstrated a simultaneous shift (excitation: $270 \mathrm{~nm} \rightarrow 262 \mathrm{~nm}$; emission: $350 \mathrm{~nm} \rightarrow 357 \mathrm{~nm}$ ), revealing that the decrease of fluorescence intensity caused by the heatalkaline pretreatment was mediated by the quenching of aromatic residue fluorescence (Christen et al., 2013).

Protein secondary structure is stabilized by the formation of disulfide bonds. Raman spectroscopy has been used to probe the conformation of protein disulfide bonds based on the frequency of S-S stretching mode (Paris et al., 2012). We first used additional experiments performed on amino acids and short peptides in solution to verify that the contribution of the low-wave-number aromatic Raman lines to the considered spectral region was negligible. Upon band decomposition, as shown in the left chart of
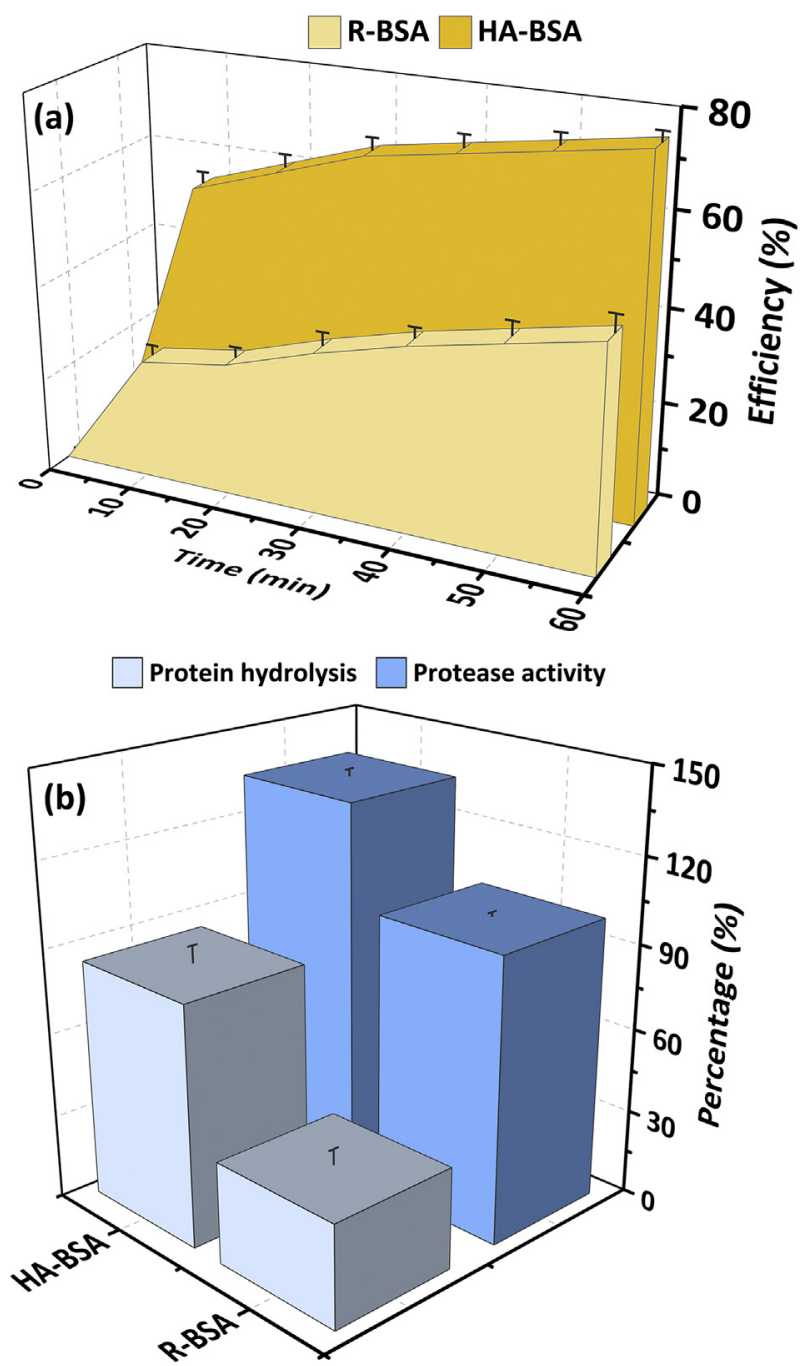

Fig. 3. Effects of pretreatment on BSA enzymatic hydrolysis. (a) Heat-alkaline pretreated (HA-BSA) and untreated (R-BSA) synthetic sludge protein samples were incubated with $50 \mathrm{mg} / \mathrm{L}$ pronase $\mathrm{E}$ for $1 \mathrm{~h}$ and analyzed for their susceptibility to proteolytic hydrolysis expressed as enzymolysis efficiency. (b) Protein hydrolysis efficiency during fermentative conversion to $\mathrm{HAc}$ at $\mathrm{pH} 9$ for $72 \mathrm{~h}$. The data are expressed as the mean \pm standard deviation of triplicate tests.

Fig. $5 d$, the presence of components in both R-BSA and HA-BSA reveals the conformational variability of disulfide linkages. Significant differences in both the wavenumbers and relative intensities of these components were also identified. First, although HA-BSA presented a large and asymmetric profile in the $480-520 \mathrm{~cm}^{-1}$ interval, fitted by two components at 505 and $516 \mathrm{~cm}^{-1}$, R-BSA displayed a symmetric monocomponent-shape peaking at $503 \mathrm{~cm}^{-1}$ in the same region. Second, although both samples presented one component at $\sim 530 \mathrm{~cm}^{-1}$, R-BSA provided an additional component at a wavenumber as high as $542 \mathrm{~cm}^{-1}$. In a previous study, the $500-550 \mathrm{~cm}^{-1}$ region in the Raman spectrum was attributed to $\mathrm{S}-\mathrm{S}$ stretching vibration mode, and peaks detected around $500-510,515-525$, and $535-545 \mathrm{~cm}^{-1}$ were characteristic of the gauche-gauche-gauche (g-g-g), gauche-gauche-trans (g-g- $t$ ), and trans-gauche-trans (t-g-t) rotamers, respectively (Paris et al., 2012). In line with the curve fitting of the band, the conformation of disulfide bridges was determined (Fig. $5 \mathrm{~d}$, right panel). In the untreated protein (R-BSA), 17 disulfide bridges were detected (11 g$\mathrm{g}-\mathrm{g}, 3 \mathrm{~g}$-g-t, and $3 \mathrm{t}-\mathrm{g}-\mathrm{t}$ ). However, heat-alkaline pretreatment decreased the number of disulfide bridges in the sample proteins to 


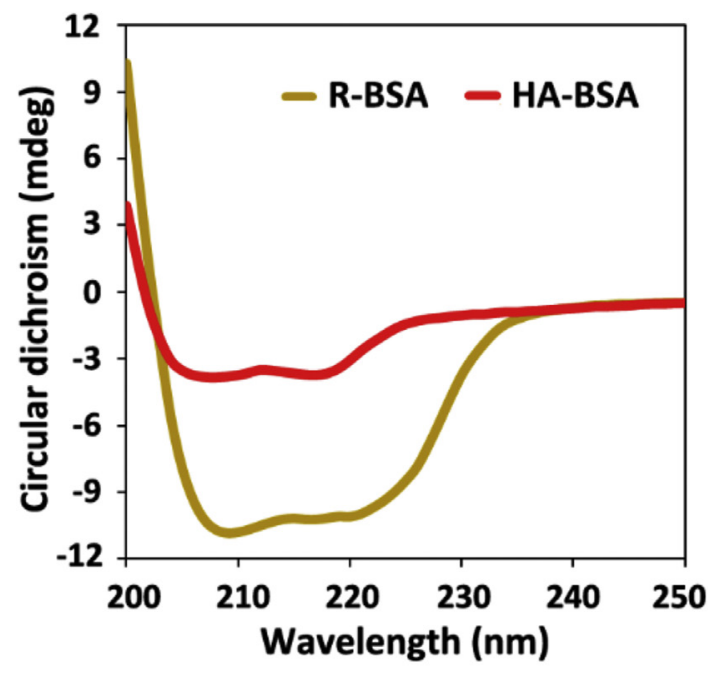

(a)

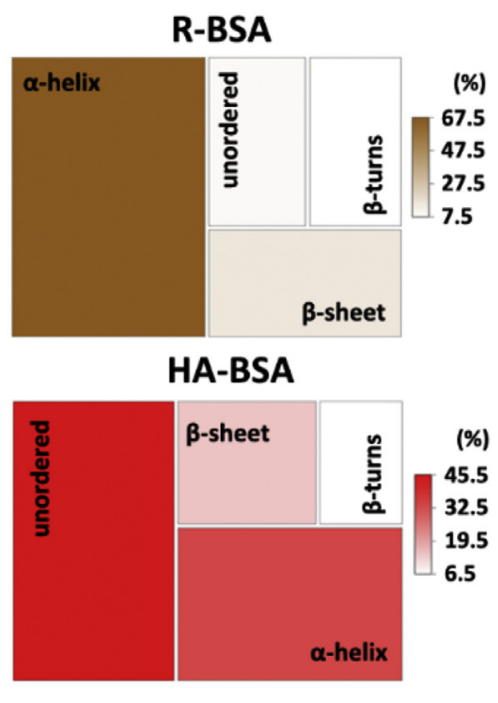

(b)

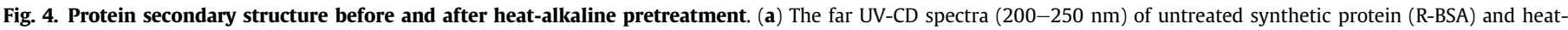

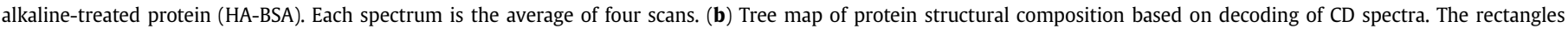

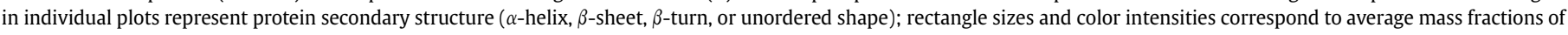
protein structures. (For interpretation of the references to color in this figure legend, the reader is referred to the web version of this article.)
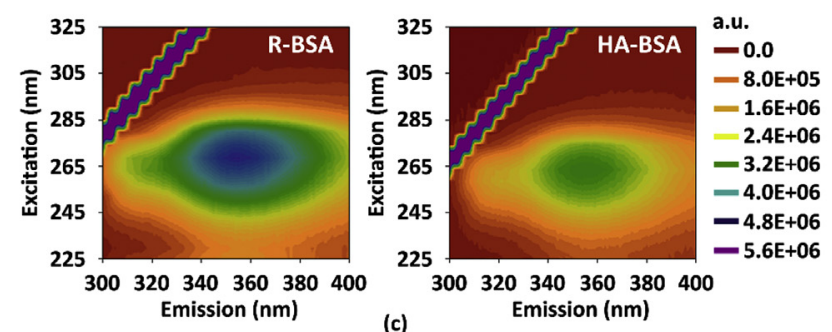

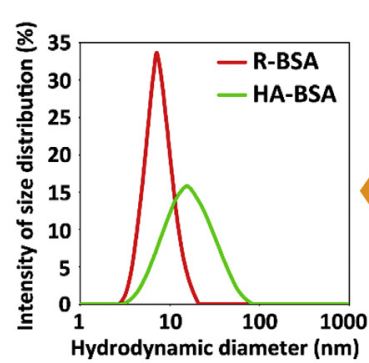

(b) (c)

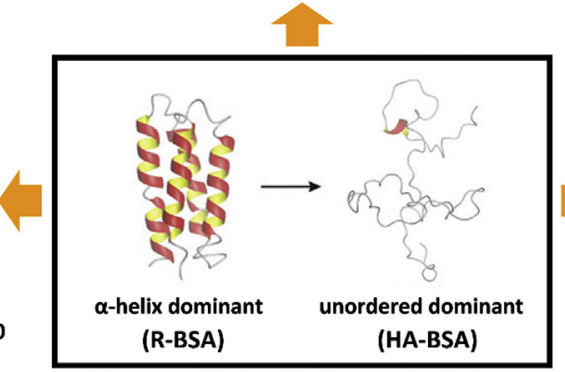

(a)

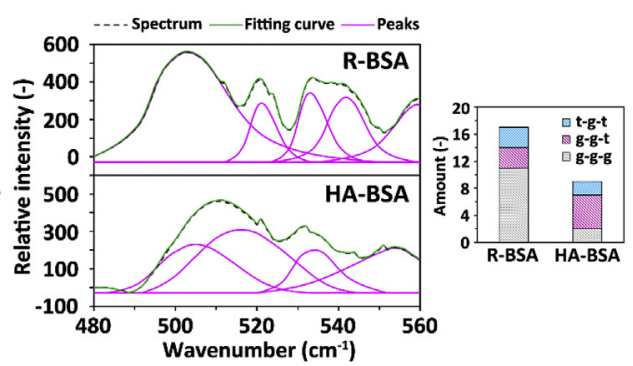

(d)

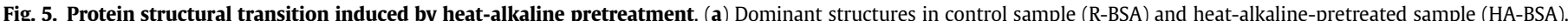

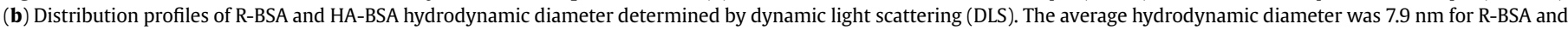

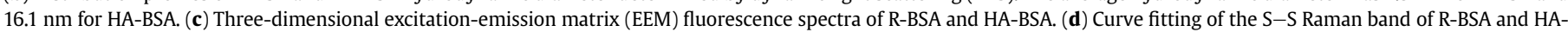

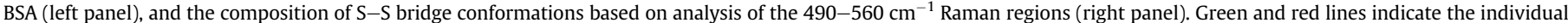

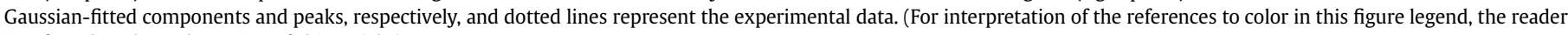
is referred to the web version of this article.)

9 while simultaneously increasing the g-g-t conformation (2 g-g-g, $5 \mathrm{~g}$-g-t, and $2 \mathrm{t}-\mathrm{g}-\mathrm{t}$ ), illustrating that heat-alkaline pretreatment not only destroyed protein disulfide bonds but also altered the protein conformation.

It is well known that hydrolysis is the rate-limiting step because the cell wall and extracellular polymeric substances in sludge will impose physic-chemical barriers to the hydrolysis of intracellular organic matters. Numerous studies have reported that heat and alkaline pretreatment among other methods play a significantly beneficial role in sludge acidification since they can facilitate extensive solubilization of organic matters and then increase bioavailability of substrates for subsequent VFAs formation (Kim et al., 2003; Vlyssides and Karlis, 2004; Dogan and Sanin, 2009; Chen et al., 2007). However, since soluble protein (BSA) was used here as the main substrate to explore the effects of the heatalkaline stimulation in relation to HAc production (see Sub Section 3.1), the findings implied that there should be a new insight into the mechanisms in relation to HAc augmentation beyond the well-known solubilization. With reference to the above multiple analyses, now it is quite evident that the heat-alkaline 
pretreatment results in the simultaneous occurrence of both protein fragmentation and denaturation, which has additive effects on protein hydrolysis and susceptibility to proteolytic degradation and therefore, the increment of HAc yield in the process.

\subsection{Verification of the combined technology using HAc yield from real WAS}

After mechanistic investigations, the feasibility of using heatalkaline pretreatment combined with fermentation at $\mathrm{pH} 9$ for augmentation of HAc production was tested in the reactor fed with real WAS. As indicated in Table 1, the HAc production of the control (no pretreatment, $\mathrm{pH} 7$ fermentation) was only $0.08 \pm 0.02 \mathrm{~g} \mathrm{COD} / \mathrm{g}$ COD after $72 \mathrm{~h}$ of fermentation, but heat-alkaline pretreatment combined with the fermentation at alkaline $\mathrm{pH}$ increased the yield by more than three-fold $(0.31 \pm 0.04 \mathrm{~g}$ COD/g COD $)$. Sludge hydrolysis was also observed in the tests, and the SCOD at alkaline fermentation ( $\mathrm{pH} \mathrm{9)}$ was significantly higher than that at neutral fermentation ( $7.93 \pm 0.22$ vs. $2.55 \pm 0.17 \mathrm{~g}$ COD/L, respectively), as observed by other researchers (Liu et al., 2012b). As further demonstrated in Table 1, a much higher total VFA production $(0.58 \pm 0.03$ vs. $0.17 \pm 0.01 \mathrm{~g} \mathrm{COD} / \mathrm{g}$ COD $)$ was found in the HA-WAS reactor with fermentation at $\mathrm{pH} 9$, which was in line with greater values of protein utilization ( $79.5 \pm 3.2 \mathrm{vs.} 20.1 \pm 2.2 \%$, respectively) and ammonia concentration $(291 \pm 18$ vs. $65 \pm 3 \mathrm{mg} \mathrm{N} / \mathrm{L}$, respectively) in the HA-WAS fed reactor than those in the R-WAS fed reactor. This is because the ammonia was produced during the conversion of amino acids to VFAs by the deamination reaction. Moreover, heat treatment of the seeding sludge significantly reduced the $\mathrm{CH}_{4}$ yield during the fermentative processes (see Fig. S3). Nevertheless, the $\mathrm{CH}_{4}$ yield of the R-WAS reactor at $\mathrm{pH} 7$ was much higher than that of the HA-WAS reactor at $\mathrm{pH}$ 9. It is well known that the optimum $\mathrm{pH}$ range for the growth of methanogens is 6.8-7.2, and the $\mathrm{CH}_{4}$ yield with the microbiology results above are consistent with this range. On the contrary, more $\mathrm{H}_{2}$ was produced in the HA-WAS reactor at $\mathrm{pH} 9$, which agreed with previous outcomes (Cai et al., 2004). In the tests, HA-WAS included a variety of organic matter such as protein, carbohydrate and lipids and presented higher substrate concentrations than HA-BSA; it was therefore expected the HA-WAS-fed reactor would exhibit a higher HAc yield in comparison to the reactor fed with HA-BSA. However, as shown in Fig. 1, the HAc generation from HA-BSA was $0.36 \pm 0.01 \mathrm{~g} \mathrm{COD} / \mathrm{g}$ COD (or $0.502 \pm 0.021 \mathrm{~g} / \mathrm{g}$ protein), which was slightly higher than that from HA-WAS. The activity of the two key enzymes relevant to HAc production with HA-BSA was higher than that with HA-WAS (Table S1), suggesting that more organic matter was converted to HAc in the reactor fed with HA-BSA. This finding also implies that the difference in HAc production between HAWAS and HA-BSA resulted from different microbe-mediated reactions rather than from different availability of substrates. In addition, it is clear that HAc originates from the amino acids conversion during protein fermentation, whereas amino acids exhibit significantly different size and structure and are mediated by different metabolic pathways (Ramsay and Pullammanappallil, 2001). In this work, HA-WAS contained multiple proteins and was different from BSA in protein type and amino acid composition, which also probably contributed to the difference in HAc generation. Further studies are required to elucidate these findings. Consistent with the increase in HAc yield, the heat-alkaline pretreatment also increased protein utilization efficiency, which was three-fold higher than that of the untreated control.

Overall, the yields of total VFAs and individual HAc produced from the real WAS (i.e., $0.58 \mathrm{~g}$ COD/g COD and $0.31 \mathrm{~g}$ COD/g COD, respectively) were found to be significantly higher than that reported in previous studies (Morgan-Sagastume et al., 2011; Yuan et al., 2006; Tan et al., 2012; Feng et al., 2009), suggesting the use of the combined technology to augment sludge-derived HAc yield was feasible. Furthermore, although the present work provided detailed evidence to verify the mechanism by which the proteins change (fragmentation and denaturation) under the condition of the heat-alkaline pretreatment, and presented information on its effects on HAc accumulation, comparative studies with an expanded coverage of pretreatment approaches are still essential to identify the most efficient option and to decipher the mechanisms in relation to augmented HAc generation from a multidisciplinary perspective.

\subsection{Economic assessment}

In Table 2, the economic potential of the combined strategy for HAc production was further assessed by means of a scenario analysis based on the experimental results and literature data obtained. In the focused scenario, the sewage sludge is initially fermented to HAc by utilizing the combined strategy (heat-alkaline pretreatment plus fermentation at pH 9), and the dewatered residue is then disposed of at an off-plant landfill, while the produced HAc is assumed to be used to hybrid power generation for revenue estimation. In addition, a baseline scenario in which the sewage sludge is converted to HAc using the control method (no pretreatment plus fermentation at $\mathrm{pH} 7$ ), and the other processes were the same as described in the focused scenario. It should be noted that, in the former experimental parts, $6 \mathrm{M} \mathrm{NaOH}$ was applied to ensure alkaline conditions and substantial amounts of sodium ions present in the reactors might have effects on the bioprocess of HAc formation. However, it also has been observed in the literature that the separation of the solid with the liquid in the dewatering process after alkaline fermentation might not be much easier than the traditional fermentation processes because of the existing of the $\mathrm{NaOH}$ in the fermented sludge (Lee et al., 2014). Furthermore, the use of $\mathrm{Ca}(\mathrm{OH})_{2}$ in adjusting alkaline conditions was found to exhibit nearly the same effect on VFA production and sludge reduction as that of $\mathrm{NaOH}$, along with additional benefits on improved sludge dewatering, decreased chemical costs, and greater fermentation liquid recovery efficiency (Li et al., 2011). In this respect, $\mathrm{Ca}(\mathrm{OH})_{2}$ seems to be more feasible than $\mathrm{NaOH}$ in the applications of tomorrow and therefore, it was used to assess the cost of alkaline pretreatment and fermentation in the focused scenario. Table 2 indicates that the benefit of the focused scenario arises from the substantial reduction of fordisposal sludge and the increased revenue from HAc-based bioenergy production, despite the unavoidable chemical and energy consumption costs of the combination of sludge pretreatment and

Table 1

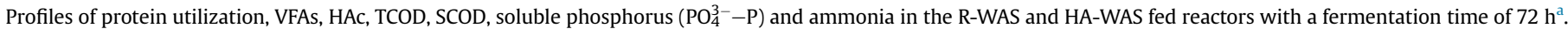
Protein utilization (\%) VFA yield (g COD/g COD) HAc yield (g COD/g COD) TCOD (g COD/L) SCOD (g COD/L) NH N $_{4}^{+}-\mathrm{N}(\mathrm{mg} \mathrm{N} / \mathrm{L}) \quad \mathrm{PO} 3--\mathrm{P}(\mathrm{mg} \mathrm{P} / \mathrm{L})$ 
Table 2

Preliminary economic analysis of the combined strategy for sludge-derived HAc production.

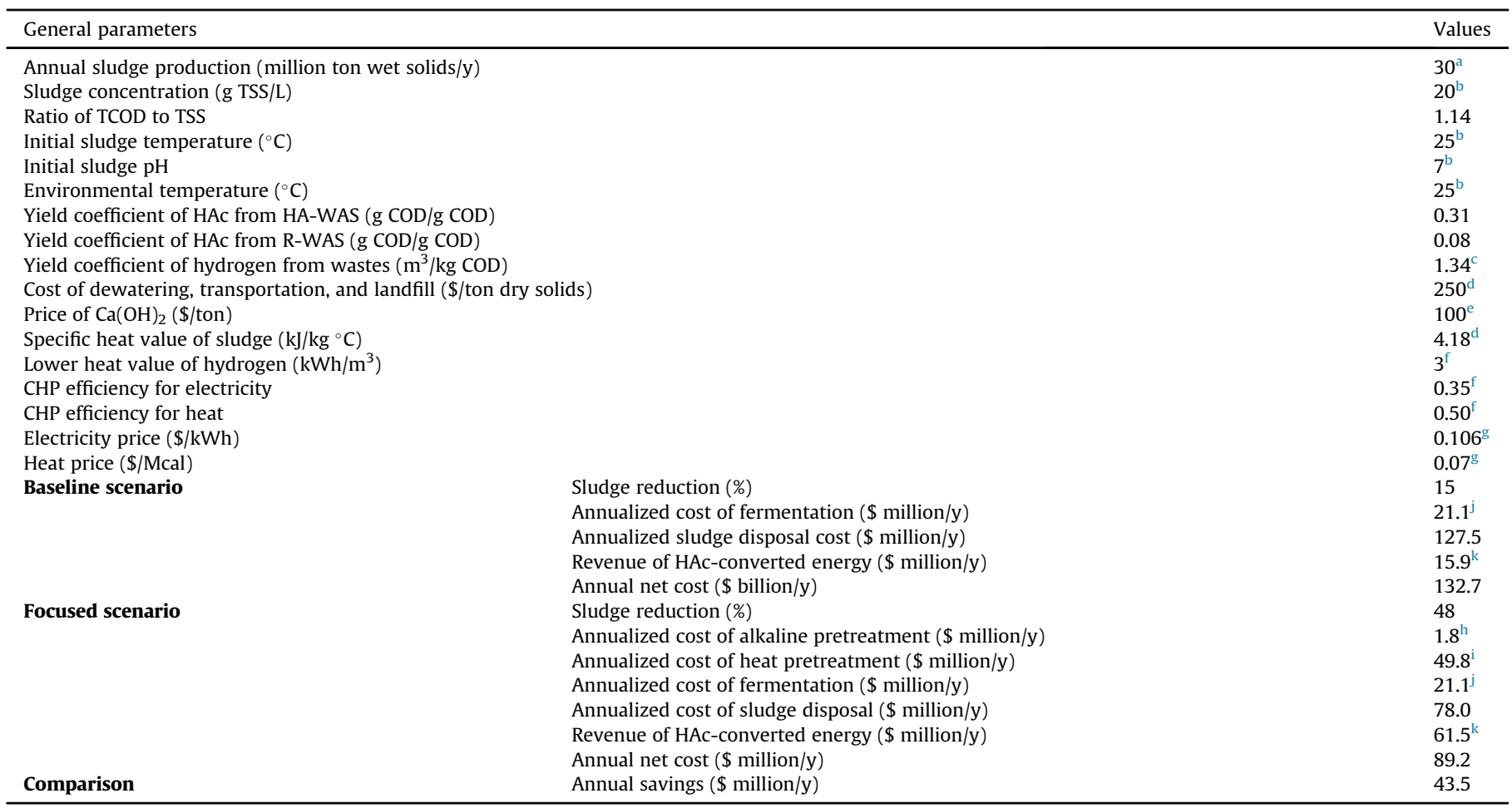

a Estimated data for China (Khan et al., 2013).

b Based on our previous field survey.

c The maximum value reported (Lu et al., 2009).

d Literature values (Dhar et al., 2012).

e Data from http://www.alibaba.com.

f Combined heat and power (CHP) system was used (Monlau et al., 2015).

$g$ Historical prices (Cho et al., 2014).

${ }^{\mathrm{h}}$ Based on the $\mathrm{Ca}(\mathrm{OH})_{2}$ usage for alkaline treatment of sludge at $\mathrm{pH} 12$.

${ }^{i}$ Estimated from the difference in the energy needed to heat the sludge to the pretreatment temperature and the recovery of heat from the thermal pretreated sludge (Dhar et al., 2012)

${ }^{\mathrm{j}}$ Estimated from the energy costs to operate the fermentation systems (Metcalf and Eddy 2003) and the heat capture from the fermented residue (Dhar et al., 2012).

${ }^{\mathrm{k}}$ Hydrogen generation using HAc as substrate; the biohydrogen was converted via CHP, and the revenue was based on the price of hybrid power.

fermentation. Overall, this strategy would result in approximately $\$ 43.5$ million savings per annum with added benefits such as waste reduction and greater biofuel production in comparison to the baseline scenario. Nevertheless, it should be also noted that the cost of the heat pretreatment was much significantly higher than that of the alkaline stimulation in the focused scenario (49.8 \$ million/y vs. $1.8 \$$ million/y), which may diminish the beneficial role of the pretreatment component in the whole strategy since the yield of HAc from HA-WAS might not be extremely greater than that from A-WAS, even if further verification is still needed. Therefore, feasibility studies with a broader range of pretreatment methods are necessary to complete the picture and to identify key aspects that require further cost-benefit improvement. Further, this preliminary economic analysis was conducted mainly based on the laboratory-scale parameters in the present study, and some uncertainties might exist in the expected results since the fullscale system would behave differently in terms of HAc production, sludge reduction, and downstream applications. Considering that the sludge-derived HAc production and its downstream applications is an emerging research field with several unexplored facets, it is understandable that the current analysis conducted in the work only addressed some of the components needed for a comprehensive evaluation. Therefore, larger-scale trials are required to evaluate the economic feasibility of this combined technology.

\section{Conclusions}

We investigated a combined strategy to enhance HAc yield from WAS fermentation through structural manipulation of the sludge protein component. Specifically, the heat-alkaline pretreatment caused protein fragmentation and simultaneously, increased the efficiency of protein denaturation by destroying disulfide bonds and inducing protein unfolding, which subsequently improved protein susceptibility to proteolytic cleavage and hydrolysis, resulting in augmentation of HAc yields. In addition, the validation of the combined strategy for sludge-derived HAc production and the economic evaluation both confirm the potential feasibility of this a priori technology for waste-to-energy applications.

\section{Acknowledgments}

We are grateful to the National Natural Science Foundation of China (Nos. 51408589 and 51138009), and the State Key Joint Laboratory of Environment Simulation and Pollution Control of China (No. 14Z03ESPCR) for their financial support.

\section{Appendix A. Supplementary information}

Supplementary information related to this article can be found at http://dx.doi.org/10.1016/j.watres.2015.10.055. 


\section{References}

Ajandouz, E.H., Desseaux, V., Tazi, S., Puigserver, A., 2008. Effects of temperature and $\mathrm{pH}$ on the kinetics of caramelisation, protein cross-linking and Maillard reactions in aqueous model systems. Food Chem. 107 (3), 1244-1252.

Bermejo-Barrera, P., Fernandez-Nocelo, S., Moreda-Pineiro, A., Bermejo-Barrera, A. 1999. Usefulness of enzymatic hydrolysis procedures based on the use of pronase $\mathrm{E}$ as sample pre-treatment for multi-element determination in biologica materials. J. Anal. Atomic Spectrom. 14 (12), 1893-1900.

Bhattacharya, M., Jain, N., Bhasne, K., Kumari, V., Mukhopadhyay, S., 2011. pHinduced conformational isomerization of bovine serum albumin studied by extrinsic and intrinsic protein fluorescence. J. Fluoresc. 21 (3), 1083-1090.

Cai, M.L., Liu, J.X., Wei, Y.S., 2004. Enhanced biohydrogen production from sewage sludge with alkaline pretreatment. Environ. Sci. Technol. 38 (11), 3195-3202.

Chae, K.J., Choi, M.J., Lee, J.W., Kim, K.Y., Kim, I.S., 2009. Effect of different substrates on the performance, bacterial diversity, and bacterial viability in microbial fuel cells. Bioresour. Technol. 100 (14), 3518-3525.

Chen, Y.G., Jiang, S., Yuan, H.Y., Zhou, O., Gu, G.W., 2007. Hydrolysis and acidification of waste activated sludge at different pHs. Water Res. 41 (3), 683-689.

Cho, S.K., Ju, H.J., Lee, J.G., Kim, S.H., 2014. Alkaline-mechanical pretreatment process for enhanced anaerobic digestion of thickened waste activated sludge with a novel crushing device: performance evaluation and economic analysis. Bioresour. Technol 165, 183-190.

Christen, L., Lai, C.T., Hartmann, B., Hartmann, P.E., Geddes, D.T., 2013. The effect of UV-C pasteurization on bacteriostatic properties and immunological proteins of donor human milk. PLoS One 8 (12).

Dangerman, A., Schellnhuber, H.J., 2013. Energy systems transformation. Proc. Natl. Acad. Sci. U. S. A. 110 (7), E549-E558.

Dhar, B.R., Nakhla, G., Ray, M.B., 2012. Techno-economic evaluation of ultrasound and thermal pretreatments for enhanced anaerobic digestion of municipal waste activated sludge. Waste Manag 32 (3), 542-549.

Dogan, I., Sanin, F.D., 2009. Alkaline solubilization and microwave irradiation as a combined sludge disintegration and minimization method. Water Res. 43 (8), 2139-2148.

Engle, M., Li, Y.H., Woese, C., Wiegel, J., 1995. Isolation and characterization of a novel alkalitolerant thermophile, anaerobranca-horikoshii gen-nov, sp-nov. Int J. Syst. Bacteriol. 45 (3), 454-461.

Fei, Q., Chang, H.N., Shang, L.A., Choi, J.D.R., Kim, N., Kang, J., 2011. The effect of volatile fatty acids as a sole carbon source on lipid accumulation by Cryptococcus albidus for biodiesel production. Bioresour. Technol. 102 (3), 2695-2701.

Feng, L.Y., Chen, Y.G., Zheng, X., 2009. Enhancement of waste activated sludge protein conversion and volatile fatty acids accumulation during waste activated sludge anaerobic fermentation by carbohydrate substrate addition: the effect of pH. Environ. Sci. Technol. 43 (12), 4373-4380.

Freguia, S., Teh, E.H., Boon, N., Leung, K.M., Keller, J., Rabaey, K., 2010. Microbial fue cells operating on mixed fatty acids. Bioresour. Technol. 101 (4), 1233-1238.

Gorlenko, V., Tsapin, A., Namsaraev, Z., Teal, T., Tourova, T., Engler, D., Mielke, R., Nealson, K., 2004. Anaerobranca californiensis sp nov., an anaerobic, alkalithermophilic, fermentative bacterium isolated from a hot spring on Mono Lake. Int. J. Syst. Evol. Microbiol. 54, 739-743.

Greenfield, N.J., 2006. Using circular dichroism spectra to estimate protein secondary structure. Nat. Protoc. 1, 2876-2890.

Halabi, N., Rivoire, O., Leibler, S., Ranganathan, R., 2009. Protein sectors: evolutionary units of three-dimensional structure. Cell 138 (4), 774-786.

Jie, W.G., Peng, Y.Z., Ren, N.Q., Li, B.K., 2014. Volatile fatty acids (VFAs) accumulation and microbial community structure of excess sludge (ES) at different pHs. Bioresour. Technol. 152, 124-129.

Khan, S., Wang, N., Reid, B.J., Freddo, A., Cai, C., 2013. Reduced bioaccumulation of PAHs by Lactuca satuva L. grown in contaminated soil amended with sewage sludge and sewage sludge derived biochar. Environ. Pollut 175, 64-68.

Kim, J., Park, C., Kim, T.H., Lee, M., Kim, S., Kim, S.W., Lee, J., 2003. Effects of various pretreatments for enhanced anaerobic digestion with waste activated sludge. J. Biosci. Bioeng. 95 (3), 271-275.

Lee, W.S., Chua, A.S.M., Yeoh, H.K., Ngoh, G.C., 2014. A review of the production and applications of waste-derived volatile fatty acids. Chem. Eng. J. 235, 83-99.

Li, X.A., Chen, H., Hu, L.F., Yu, L., Chen, Y.G., Gu, G.W., 2011. Pilot-scale waste activated sludge alkaline fermentation, fermentation liquid separation, and application of fermentation liquid to improve biological nutrient removal. Environ. Sci. Technol. 45 (5), 1834-1839.

Liu, W.Z., Huang, S.C., Zhou, A.J., Zhou, G.Y., Ren, N.Q., Wang, A.J., Zhuang, G.Q., 2012a. Hydrogen generation in microbial electrolysis cell feeding with fermentation liquid of waste activated sludge. Int. J. Hydrogen Energy 37 (18), 13859-13864.

Liu, H., Wang, J., Liu, X.L., Fu, B., Chen, J., Yu, H.Q., 2012b. Acidogenic fermentation of proteinaceous sewage sludge: effect of pH. Water Res. 46 (3), 799-807.

Lu, L., Ren, N., Xing, D., Logan, B.E., 2009. Hydrogen production with effluent from an ethanol-H-2-coproducing fermentation reactor using a single-chamber microbial electrolysis cell. Biosens. Bioelectron 24 (10), 3055-3060.

Lu, L., Xing, D.F., Liu, B.F., Ren, N.Q., 2012. Enhanced hydrogen production from waste activated sludge by cascade utilization of organic matter in microbia electrolysis cells. Water Res. 46 (4), 1015-1026.

Metcalf, Eddy, 2003. Wastewater Engineering: Treatment and Reuse. McGraw Will, New York.

Miron, Y., Zeeman, G., Van Lier, J.B., Lettinga, G., 2000. The role of sludge retention time in the hydrolysis and acidification of lipids, carbohydrates and proteins during digestion of primary sludge in CSTR systems. Water Res. 34 (5), 1705-1713.

Mitchell, W.J., 1998. In: Poole, R.K. (Ed.), Advances in Microbial Physiology, vol. 39, pp. $31-130$.

Mitra, R.K., Sinha, S.S., Pal, S.K., 2007. Hydration in protein folding: thermal unfolding/refolding of human serum albumin. Langmuir 23 (20), 10224-10229.

Monlau, F., Kaparaju, P., Trably, E., Steyer, J.P., Carrere, H., 2015. Alkaline pretreatment to enhance one-stage $\mathrm{CH} 4$ and two-stage $\mathrm{H}-2 / \mathrm{CH} 4$ production from sunflower stalks: mass, energy and economical balances. Chem. Eng. J 260, $377-385$.

Morgan-Sagastume, F., Pratt, S., Karlsson, A., Cirne, D., Lant, P., Werker, A., 2011. Production of volatile fatty acids by fermentation of waste activated sludge pretreated in full-scale thermal hydrolysis plants. Bioresour. Technol. 102 (3), 3089-3097.

Morgan-Sagastume, F., Hjort, M., Cirne, D., Gerardin, F., Lacroix, S., Gaval, G., Karabegovic, L., Alexandersson, T., Johansson, P., Karlsson, A., Bengtsson, S. Arcos-Hernandez, M.V., Magnusson, P., Werker, A., 2015. Integrated production of polyhydroxyalkanoates (PHAs) with municipal wastewater and sludge treatment at pilot scale. Bioresour. Technol. 181, 78-89.

Nasidi, M., Akunna, J., Deeni, Y., Blackwood, D., Walker, G., 2010. Bioethanol in Nigeria: comparative analysis of sugarcane and sweet sorghum as feedstock sources. Energy Environ. Sci. 3 (10), 1447-1457.

Paris, G., Kraszewski, S., Ramseyer, C., Enescu, M., 2012. About the structural role of disulfide bridges in serum albumins: evidence from protein simulated unfolding. Biopolymers 97 (11), 889-898.

Prowe, S.G., Antranikian, G., 2001. Anaerobranca gottschalkii sp nov., a novel thermoalkaliphilic bacterium that grows anaerobically at high $\mathrm{pH}$ and temperature. Int. J. Syst. Evol. Microbiol. 51, 457-465.

Ramsay, I.R., Pullammanappallil, P.C., 2001. Protein degradation during anaerobic wastewater treatment: derivation of stoichiometry. Biodegradation 12 (4), $247-257$.

Reed, R.G., Feldhoff, R.C., Peters, T., 1976. Fragments of bovine serum-albumin produced by limited proteolysis - complementary behavior of 2 large fragments. Biochemistry 15 (24), 5394-5398.

Renard, D., Lavenant-Gourgeon, L., Lapp, A., Nigen, M., Sanchez, C., 2014. Enzymatic hydrolysis studies of arabinogalactan-protein structure from Acacia gum: the self-similarity hypothesis of assembly from a common building block. Carbohydr. Polym. 112, 648-661.

Roman, H.J., Burgess, J.E., Pletschke, B.I., 2006. Enzyme treatment to decrease solids and improve digestion of primary sewage sludge. Afr. J. Biotechnol. 5 (10), 963-967.

Sheng, G.P., Yu, H.Q., 2006. Characterization of extracellular polymeric substances of aerobic and anaerobic sludge using three-dimensional excitation and emission matrix fluorescence spectroscopy. Water Res. 40 (6), 1233-1239.

Tan, R., Miyanaga, K., Uy, D., Tanji, Y., 2012. Effect of heat-alkaline treatment as a pretreatment method on volatile fatty acid production and protein degradation in excess sludge, pure proteins and pure cultures. Bioresour. Technol. 118, $390-398$.

Tuma, R., 2005. Raman spectroscopy of proteins: from peptides to large assemblies, J. Raman Spectrosc. 36 (4), 307-319.

Uyar, B., Eroglu, I., Yucel, M., Gunduz, U., 2009. Photofermentative hydrogen production from volatile fatty acids present in dark fermentation effluents. Int. J. Hydrogen Energy 34 (10), 4517-4523.

Vlyssides, A.G., Karlis, P.K., 2004. Thermal-alkaline solubilization of waste activated sludge as a pre-treatment stage for anaerobic digestion. Bioresour. Technol. 91 (2), 201-206.

Wang, Y.Y., Zhang, Y.L., Wang, J.B., Meng, L., 2009. Effects of volatile fatty acid concentrations on methane yield and methanogenic bacteria. Biomass Bioenergy 33 (5), 848-853.

Wang, X., Liu, J., Ren, N.-Q., Yu, H.-Q., Lee, D.-J., Guo, X., 2012. Assessment of multiple sustainability demands for wastewater treatment alternatives: a refined evaluation scheme and case study. Environ. Sci. Technol. 46 (10), 5542-5549.

Wang, X., Liu, J.X., Qu, B., Ren, N.Q., Qu, J.H., 2013. Role of carbon substrates in facilitating energy reduction and resource recovery in a traditional activated sludge process: investigation from a biokinetics modeling perspective. Bioresour. Technol. 140, 312-318.

Wang, X., McCarty, P.L., Liu, J.X., Ren, N.Q., Lee, D.J., Yu, H.Q., Qian, Y., Qu, J.H., 2015. Probabilistic evaluation of integrating resource recovery into wastewater treatment to improve environmental sustainability. Proc. Natl. Acad. Sci. U. S. A. 112 (5), 1630-1635.

Xiao, N., Chen, Y., Chen, A., Feng, L., 2014. Enhanced bio-hydrogen production from protein wastewater by altering protein structure and amino acids acidification type. Sci. Rep. 4, 3992.

Yuan, H.Y., Chen, Y.G., Zhang, H.X., Jiang, S., Zhou, Q., Gu, G.W., 2006. Improved bioproduction of short-chain fatty acids (SCFAs) from excess sludge under alkaline conditions. Environ. Sci. Technol. 40 (6), 2025-2029.

Zhang, P., Chen, Y., Zhou, Q., Zheng, X., Zhu, X., Zhao, Y., 2010. Understanding shortchain fatty acids accumulation enhanced in waste activated sludge alkaline fermentation: kinetics and microbiology. Environ. Sci. Technol. 44 (24), 9343-9348.

Zhilina, T.N., Kevbrin, V.V., Tourova, T.P., Lysenko, A.M., Kostrikina, N.A., Zavarzin, G.A., 2005. Clostridium alkalicellum sp nov, an obligately alkaliphilic cellulolytic bacterium from a soda lake in the Baikal region. Microbiology 74 (5), $557-566$. 